\title{
Un aporte de la academia a la competitividad de los artesanos y mipymes. Proyecto 17-2017
}

\section{A contribution from the academy to the competitiveness of artisans and mipymes. Project 17-2017}

\author{
Marco Fabricio Sánchez Maldonado*1, Raquel Miroslava Tinoco Egas ${ }^{1}$, Stefany Valeria Maldonado Castillo ${ }^{1}$ \\ ${ }^{1}$ Universidad Técnica de Machala, Ecuador \\ *msanchez@utmachala.edu.ec
}

DOI: https://doi.org/10.26871/killkanasocial.v5i1.766

\begin{abstract}
Resumen
Es loable como los artesanos y microempresarios esquivan adversidades de toda índole, para sobrellevar sus actividades. Desarrollar estos negocios y ser competitivos es un reto que muchas veces logran de forma empírica, o por imitación. A pesar de existir leyes, códigos y reglamentos que benefician al consumidor final al momento de realizar importaciones, el desconocimiento de estas normativas implica para empresarios y productores tener costos de producción elevados. La intermediación comercial incrementa los precios al consumidor final de maquinarias o insumos vitales para sus actividades productivas. Este factor muchas veces especulativo, es lo que pone en desventaja a los artesanos o emprendedores ecuatorianos, al tener costos operativos elevados que se reflejan en el precio final de sus productos que no pueden competir con sus pares importados, aunque existan barreras arancelarias para proteger la producción nacional. La intervención de la universidad en estos sectores (social, económico, laboral o desde el punto de vista que se quiera ver) es diversificando la visión estudiantil para atender estos emprendimientos que prometen más experiencias laborales y de aplicación de los conocimientos impartidos a los estudiantes en las aulas. Escuadrones de estudiantes identifican artesanos y microempresarios con necesidades de importación, se realizan las consultas de campo necesarias para proceder con una apropiada asesoría de importación de insumos o maquinarias que le resulte viable al potencial importador. Se ha evidenciado en muchas de estas simulaciones de importaciones, que los productos que necesitan nuestros asesorados, se comercializan localmente con márgenes de ganancia que son especulativos en sobremanera
\end{abstract}

Palabras clave: Importación, competitividad, artesanos, microempresarios.

\begin{abstract}
It is praiseworthy the way that artisans and micro entrepreneurs dodge adversities of all kinds, to endure with their activities. To develop these businesses being competitive is a challenge that many times achieve empirically, or by imitation. Despite the existence of laws, codes and regulations in benefit of the final consumer if they want to import, the ignorance of these regulations implies that the business owners have high production costs. The commercial intermediation increases the prices to the final consumer of machinery or vital inputs for their productive activities. This speculative factor often is what puts Ecuadorian artisans or entrepreneurs at a disadvantage, having high operating costs that are reflected in the final price of their products that cannot compete with its similar imported, even with tax barriers created to protect domestic production. The intervention of the university in these areas (social, economic, labor or from the point of view you want to see) is diversifying the student vision giving attention to this sector that promises more working experiences and application of the knowledge imparted to the students in the classrooms. Squads of students identify artisans and microentrepreneurs with import needs, the necessary consultations are made to proceed with a proper advice on the importation of inputs or machinery that is viable for the potential importer. It has been evidenced in many of these import simulations, that the products that our advised people need, are marketed locally with profit margins that are highly speculative.
\end{abstract}

Keywords: Imports, competitiveness, handcrafters, microentrepreneur.

\section{Introducción}

El objetivo del presente trabajo es asesorar al sector artesanal o Mipymes con necesidades de importación, en la búsqueda de cotizaciones nacionales, fronterizas o inter- nacionales, de maquinarias o insumos que sean necesarios para su actividad productiva. Además de la asesoría en las formalidades de rigor para la importación de esos productos. Este trabajo también está en línea con el proyecto 
de capacitación de ALADI (s.f.), cuyo objetivo fue dar asesoría técnica a artesanos en Pichincha, para fomentar la transición enfocado a un mercado local a uno regional.

La inserción de la microempresa en el análisis de las empresas en Ecuador establece una mayor proporción en comparación a las medianas y grandes empresas, el crecimiento de estas microempresas ha ido aumentando gracias a la iniciativa privada, algo de apoyo del Gobierno, y las nuevas estrategias que se están implementando para el mejoramiento de calidad de vida, el crecimiento productivo y económico.

La atención del gobierno se centra en la creación de leyes que beneficien al sector productivo como por ejemplo el Código Orgánico de Producción, Comercio e Inversiones (COPCI) donde entre otras cosas, se contempla las figuras de exportación e importación que dan facilidades a estas actividades comerciales en la mayoría de sus posibles figuras. Adicionalmente se encuentra el cuerpo legal de la Ley de Fomento Artesanal que focaliza su atención en los artesanos calificados. En la ejecución del proyecto se identificó más de un artesano no calificado por la Junta Nacional de Defensa del Artesano (JNDA), al cual se asesoró

identificándolo como un microempresario que no podría acogerse a lo estipulado en el artículo 9 de la Ley de fomento artesanal, sin embargo, se le socializó las alternativas de importación contempladas en el COPCI, aparte de la importación a consumo.

El apoyo gubernamental o de organizaciones sin fines de lucro, también se requiere para el sector artesanal, mediante créditos o capacitaciones, ya que el comercio internacional no puede ser accedido por el artesano sin suficientes recursos económicos, esta deficiencia ha sido poco a poco resuelta mediante el desarrollo del comercio justo. (Bringas, 2013).

Las protecciones arancelarias que aplica Ecuador en las importaciones para la protección de su producción nacional, no está bien enfocada o por lo menos al aplicarla generalmente, afecta a los productos que tienen su par en la producción nacional y también encarece a los que no se producen en el Ecuador. Muchos de los productos gravados con aranceles superiores al impuesto al valor agregado IVA, no tienen producción local y son necesarios para la producción de los artesanos o mipymes.

\section{Desarrollo}

El aporte a la economía nacional por parte del sector artesanal y mipymes es importante, según el Instituto Nacional de Estadísticas y Censos INEC, de las 843.745 empresas censadas en el Ecuador hasta el 2016, 763.636 son microempresas y su siguiente sector es la pequeña empresa con 63.400. De acuerdo con el mismo instituto, en el informe presentado en abril del 2018 de la Encuesta Estructural Empresarial ENESEM 2016 indica que; hay 203.613 entre hombres y mujeres ocupados según categoría de ocupación como artesanos, oficiales y operadores de instalaciones y maquinarias. (Instituto Nacional de Estadísticas y Censos INEC, s.f.)

En la primera etapa de la ejecución de este proyecto, utilizando el método teórico-práctico, se ha realizado la identificación de artesanos, microempresarios o emprendedores que estén interesados en importaciones. Se procede con una simulación de importación para determinar los aranceles en importación a través de la herramienta de consulta de arancel disponible en la página de aduana http: / / ecuapass.aduana.gob.ec/ ipt_server/ipt_flex/ipt_arancel.jsp Luego se ha instruido a los alumnos de la carrera de comercio exterior, en los regímenes aduaneros aplicables a las importaciones del sector asesorado (especialmente el artesanal), también se ha instruido a los estudiantes participantes, en los beneficios que la ley de fomento artesanal tiene para el sector.

Las necesidades del sector intervenido aparentemente no son prioritarias, pues al describir el producto que se desea importar, no es de vital importancia su consumo o importación. Sin embargo, luego de las primeras investigaciones de cotizaciones y de las facilidades aduaneras de importación. La necesidad del producto consultado tiene más relevancia en los planes a corto plazo del asesorado.

El desconocimiento de los procesos aduaneros y logísticos para realizar la importación es un factor común en muchos de los asesorados. La importación a consumo es básicamente con lo que inicia la asesoría, algunas de las importaciones superan el precio de factura de 2000,00 USD, por lo que las formalidades aduaneras tienden a ser más complicadas, por la obtención de la firma electrónica y la necesidad de contratar un agente afianzado de aduana.

Las importaciones provenientes de países fronterizos tienen la ventaja de poder acogerse a los regímenes aduaneros contemplados en el COPCI, como por ejemplo el régimen de Efectos personales de viajero contemplados en el artículo 215 del reglamento del código. O el régimen de Menaje de casa y Equipos profesionales contemplados en el artículo 212 del mismo reglamento. Algunos de los identificados se pueden acoger al régimen de Tráfico fronterizo especificado en el artículo 211 del mismo cuerpo legal. Adicionalmente Aboal y Zunino indica que; los efectos sobre el empleo también dependen del tipo de tecnología que se introduce, ya que de estas depende la mejora de la productividad que puedan tener las empresas y, por tanto, su capacidad de captar mayor demanda vía reducciones de precios o mayor calidad de los productos. (Aboal y Zunino, 2017)

Una vez revisadas las cotizaciones y los impuestos a pagar que tienen las mercancías se proceden con el análisis de la ley, para poder determinar la alternativa más económica para importar. Se ha replicado los servicios que la cámara chino-ecuatoriana oferta a los interesados en realizar importaciones advirtiendo de los riesgos y ventajas que tiene la comercialización con el tigre asiático. Un informe de la vialidad de la importación y su proceso 
aduanero se le entrega al artesano para que tenga en cuenta las alternativas que tiene al traer esas máquinas o insumos. Y por parte del artesano se ha obtenido una certificación de haber sido asesorado en lo referente a la importación de sus necesidades.

El apoyo gubernamental o de organizaciones sin fines de lucro, también se requiere para el sector artesanal, mediante créditos o capacitaciones, ya que el comercio internacional no puede ser accedido por el artesano sin suficientes recursos económicos, esta deficiencia ha sido poco a poco resuelta mediante el desarrollo del comercio justo. (Bringas, 2013). Con la creación del proyecto 172017 "Asesoría en importaciones a artesanos, mipymes o asociaciones de la provincia de el Oro" de la carrera de Comercio Internacional, se socializó al sector de atención, los beneficios de ley y las facilidades técnicas aduaneras a las que se pueden acoger para una formal importación.

\section{Resultados y conclusiones}

Muchos de los beneficios para los sectores productivos son desconocidos por los sectores a los cuales está dirigido. La socialización de los beneficios establecidos en el COPCI y Ley de fomento artesanal es una de las estrategias que Sarmiento del Valle indica: Puede afirmarse que las regiones podrán lograr mejores niveles de desarrollo si establecen estrategias que faciliten la competitividad. (Sarmiento del Valle, 2008). Con la intervención de 179 estudiantes de la carrera de Comercio Internacional de la Universidad Técnica de Machala se logró socializar en 133 asesorados entre artesanos y microempresarios, de los beneficios contemplados en la aplicabilidad de la ley, desconocida en algunos casos por el sector atendido.

Con la cátedra de Trámites de Importación y Exportación y Técnicas Aduaneras, correspondiente a la malla de la carrera en referencia, se ha logrado obtener resultados por encima de los declarados (80 estudiantes y 40 artesanos o mipymes) para la ejecución del proyecto. El consecuente fortalecimiento de los conocimientos de los futuros profesionales, al realizar las consultas de campo y entrevistas con profesionales del área es uno de los objetivos de la aplicación de conocimientos teóricos usando los proyectos de vinculación con los que dispone la carrera. La contribución profesional que los proyectos de vinculación aportan al estudiante es invaluable, además de fortalecer su experiencia profesional en el área

Como parte de las evidencias recogidas con la ejecución del proyecto, se tiene las certificaciones de 133 interesados en la importación directa de sus insumos o maquinarias. El evidente beneficio económico de la importación directa que representa para el artesano o mypime, documentado en las cotizaciones nacionales e internacionales, además de los detalles de los impuestos a pagar. Orienta el interés de los asesorados a mirar en mercados internacionales las alternativas para una producción más eficiente o competitiva.
En la siguiente tabla se resume la cantidad de participantes (alumnos), artesanos, asociaciones y microempresarios atendidos en los períodos académicos desde el 2017 hasta la fecha.

Tabla 1

\begin{tabular}{|c|c|c|c|c|}
\hline $\begin{array}{l}\begin{array}{l}\text { Periodo de } \\
\text { ejecución } \\
\text { del proyecto }\end{array}\end{array}$ & \begin{tabular}{|l} 
Estudiantes \\
declarados
\end{tabular} & \begin{tabular}{|l} 
Estudiantes \\
certificados
\end{tabular} & 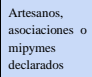 & Artesanos, asociaciones y mipymes atendidos \\
\hline $2017-1$ & 20 & 42 & 10 & $\begin{array}{l}\begin{array}{l}21 \text { asesorados entre: } 4 \text { panificadores, } 3 \text { mecánicos, } 3 \text { zapateros, } 3 \text { textileros, } 2 \\
\text { camaroneros, bisutera, tapizador, carpintero, cerrajero, latero, bananero. }\end{array} \\
\end{array}$ \\
\hline $2017-2$ & 20 & 62 & 10 & $\begin{array}{l}45 \text { asesorados entre: } 11 \text { mecánicos, } 6 \text { panaderos, } 5 \text { mipyme, } 4 \text { costureros, }, \\
\text { lateros, } 3 \text { tapiceros, } 2 \text { carpinteros, } 2 \text { peluqueros, } 2 \text { zapateros, } 2 \text { cerrajeros, } \\
\text { agricultor, asociación de costureras, imprenta, orfebre, albañil }\end{array}$ \\
\hline 2018-1 & 20 & 32 & 10 & 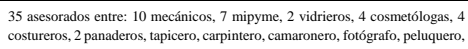 \\
\hline $2018-2$ & 20 & 43 & 10 & 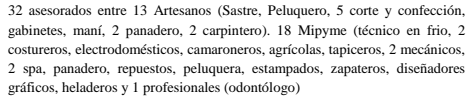 \\
\hline
\end{tabular}

Fuente: Datos recolectados con la ejecución del proyecto 17-2017

La ejecución del proyecto 17-2017 trae a la memoria la reforma de Córdova de 1918, llevando la academia a la sociedad que la necesita, no trayendo la sociedad a una academia indolente con una realidad que no está en los libros que pregona.

\section{Referencias Bibliográficas}

Aboal, D., y Zunino, G. (2017). Robotlucion. el futuro del trabajo en la integración 4.0 en américa latina. Revista Integración $y$ Comercio 42, 330. Descargado de https:// publications.iadb.org/handle/11319/ 8487?locale-attribute=es \&

ALADI. (s.f.). Capacitación a artesanos para desarrollar capacidades para exportación a paÍses de la regiÓn. Publicación DAPMDER, 22(10).

Bringas, I., B. y Capaldi. (2013). Artesanos y el comercio internacional. comercio justo. En Nuevas rutas hacia el bienestar social económico y ambiental. Chile. (Memoria del Foro Bienal Iberoamericano de Estudios del Desarrollo. Simposio de Estudios del Desarrollo)

Instituto Nacional de Estadísticas y Censos INEC. (s.f.). Descargado de http:// WWw. ecuadorencifras.gob.ec/ documentos/web-inec/Estadisticas _Economicas/Encuesta_Estructural _Empresarial/2016/Tomo_I/2016 _ENESEM_Principales

Sarmiento del Valle, S. (2008). Competitividad regional. Dimens, 6(1), 19-37.

Recibido: 23 de mayo de 2019

Aceptado: 7 de febrero de 2021 


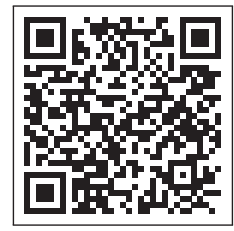

